\title{
MUHAMMAD ŠUKRī: EL PROTECTORADO ESPAÑOL EN MARRUECOS DESDE LA MARGINALIDAD
}

\author{
$M^{a}$ Dolores López Enamorado
}

\begin{abstract}
This article analyzes different facets of the Spanish Protectorate in Morocco through the work For bread alone of Muhammad Šukrī, autobiographical novel where the author verifies, through his own experience, the difficult situation that the marginalized classes lived in this period of the Moroccan history.
\end{abstract}

La autobiografía es el relato de la propia vida. Y a este género recurre Muhammad Šukrī en la redacción de sus dos obras más representativas, El pan desnudo y Tiempo de errores. Ambas constituyen la narración del itinerario biográfico de su autor desde su infancia hasta los 20 años en el caso de la primera novela, y a partir de esa edad en la segunda.

De esta autobiografía novelada, centraré mi trabajo en el análisis de El pan desnudo, dado que el ámbito cronológico en el que se sitúa esta novela se corresponde de forma aproximada con los últimos quince años del Protectorado español en Marruecos, que se inicia en 1912, y concluye en 1956. Frente a esto, la etapa en la que se desarrolla Tiempo de errores $^{2}$ queda fuera de estos años, puesto que el arranque de esta segunda novela está situado en 1956.

Por tanto, y tomando como base El pan desnudo, en primer lugar quiero hacer una breve alusión a la edición castellana, magnífica traducción del árabe realizada por Abdellah Djbilou', pero cuyo título considero que no refleja fielmente el concepto del original árabe,

\footnotetext{
1. L. Mouzouni, en su libro Le roman marocain de langue française (París 1987) 162-163, señala, refiriéndose a la obra de Šukrī, El pan desnudo, que se da en ella "una acumulación de garantías para no dejar ninguna duda sobre la naturaleza autobiográfica del relato". Y apunta las siguientes: a.- La confirmación hecha por el propio autor, quien declara que es una novela-autobiográfica-picaresca. b.- La del editor, que, en la edición francesa [Le pain nu. Traducción de Tahar Ben Jelloun. París: Maspero, 1980], habla de récit autobiographique. c.- La de Tahar Benjelloun, que, en el prefacio de esa misma edición, identifica al autor con el personaje. d.- La identificación que se da, en el seno de la novela, entre el autor y el narrador, a través del relato en primera persona. A propósito de la autobiografía en Muhammad Šukrī, véase el breve trabajo de J. M. Ridao, "Chukri y el género autobiográfico", Cálamo 10 (1986) 49.

2. Zaman al-ajtā'. Versión castellana: M. Chukri, Tiempo de errores (traducido por Karima Hajjaj y Malika Embarek) (Madrid 1995).

3. M. Chukri, El pan desnudo (Barcelona $1988^{2}$ ). Traducción del árabe por Abdellah Djbilou, con prólogo de Juan
} 
al-Jubzal-Hōẫ, cuya versión más adecuada sería la dada por el profesor Martínez Montávez, Pan a secas", u otras como "Sólo pan". La presunta "desnudez" del pan nada sugiere al lector español de la escasez y el hambre que ha de pasar el protagonista quien, en numerosas ocasiones, se tiene que contentar con un pedazo de "pan solo" o de "pan a secas". En este sentido, narra Šukrī en el primer capítulo de esta obra:

"La acompañaba al gran zoco, donde comprábamos el pan duro que vendían los mendigos debajo del árbol del Santo Mojfi. Lo ponía a hervir en agua con un poco de aceite y especias, y, a veces, sólo en agua".

A fin de delimitar de forma exacta la etapa en la que se desarrolla la acción del Pan desnudo, he recurrido tanto a las referencias cronológicas incluidas en la obra, como a los datos de la propia biografía del autor recogidos en entrevistas y estudios. El periodo que recorre Šukrī en esta novela se inicia en los primeros años de la década de los cuarenta, puesto que el autor nace en marzo de 1935 en la aldea rifeña de Benī Šìar, en la provincia de Nador, y, según señala él mismo en la obra, se marchó de esta aldea con 5 ó 6 años?:

"Me recordó que cuando se fue del Rif yo tenía cinco a seis años".

Esta partida de la aldea originaria es narrada en el primer capítulo de El pan desnudo y, por tanto, la obra se inicia en 1940 ó 1941. Respecto a la fecha de conclusión de la novela, en el último capítulo es de nuevo el autor quien aporta el dato necesario para delimitar su obra, pues señala:

"Tengo 20 años y no sé firmar siquiera".

Así, la obra finaliza en el periodo comprendido entre marzo de 1955 y el mismo mes de 1956, coincidiendo de forma muy aproximada con las fechas en las que se firman los acuerdos de independencia de Marruecos, tanto en lo que respecta a la zona de Protectorado francés (2 de marzo de 1956) como español (7 de abril del mismo año).

Un importante número de prosistas marroquíes han utilizado, de una u otra manera, el tema del Protectorado como telón de fondo de sus obras ${ }^{10}$. En el caso de Šukrī, el pasado

Goytisolo. Esta misma traducción fue publicada en Barcelona 1992; y, posteriormente, en Madrid 1996. Las citas que hago en este trabajo van referidas a la edición de 1988.

4. P. Martínez Montávez, Introducción a la literatura árabe moderna (Madrid 1985) 231.

5. Existe una traducción en valenciano, cuyo título, en mi opinión, tampoco es acertado: El Pa de cada día (Alzira 1990).

6. M. Šukrī, El pan desnudo (Barcelona $1988^{2}$ ) 18. En adelante, y en las citas de esta obra, me referiré a ella como Pan.

7. F. de Ágreda Burillo, Encuesta sobre literatura marroqui actual (Madrid 1975) 45. Estos datos de la biografía de Muhammad Šukrī son confirmados a lo largo de la propia obra objeto de este estudio.

8. Pan, 44.

9. Pan, 157.

10. F. Ramos López, "Algunas visiones del pasado colonial como eje central en el surgimiento del relato árabe en Marruecos", Philologia Hispalensis 10 (1995) 265, señala : "Ya sea desde un punto de vista romántico-sentimental, histórico, realista, simbólico, existencialista u otros, el colonialismo está presente en casi toda la producción narrativa marroquí del siglo XX". 
colonial forma parte de sus recuerdos, de sus vivencias, y, como tal, al narrar su autobiografía, determinados hechos particulares aparecen en la obra fuertemente vinculados con circunstancias propias de la etapa del Protectorado ${ }^{11}$. En este sentido, y en mi opinión, el interés de analizar cualquier periodo histórico a través de obras literarias centradas en ellos radica en la libertad que tienen los autores para manejar los datos, y en la subjetividad con la que éstos perciben una realidad vivida o conocida. En este sentido, y a diferencia de la visión que del Protectorado español en Marruecos aportan los estudios históricos con sus análisis, sus datos y sus estadísticas, la obra literaria de Šukrī parte de una perspectiva subjetiva, personal: la del propio protagonista, que vive los acontecimientos, que sufre las consecuencias inmediatas de una determinada coyuntura política y social. Y, en el caso de El pan desnudo, es además la visión desde la clase menos favorecida, del estrato social más bajo del entramado de la época. Porque Šukrī no pertenece a la clase beneficiaria de la injerencia europea en Marruecos. Por el contrario, el autor forma parte del mundo de aquéllos que lucharon a diario contra el hambre y por la simple supervivencia, siempre con escasas posibilidades de salir de esa miseria a la que un Šukrī niño ya parece irremediablemente abocado desde las primeras páginas de El pan desnudo.

No voy a recorrer aquí los acontecimientos políticos que marcaron los últimos quince años del Protectorado, puesto que el autor ni siquiera los menciona, salvo escasísimas excepciones. Desde su analfabetismo, desde ese submundo de drogas, prostitución, hambre y violencia, los acontecimientos de la vida política del país se diluyen, y el pueblo, esa masa inculta y desfavprecida de la sociedad, sólo sufre sus consecuencias más inmediatas. De esta forma, el lector es lanzado a los suburbios de las diversas ciudades por las que el joven Šukrī debió pasar, a su lucha diaria y al sufrimiento casi continuo, aportando la visión de la otra cara del Protectorado: su faceta más sórdida y lúgubre, vivida por una de sus víctimas. Como señala Juan Goytisolo en el prólogo de la edición castellana de El pan desnudo, es "en efecto la historia real, sufrida, de uno de nuestros supuestos protegidos bajo el manto de una falaz misión civilizadora y la algazara estridente de la mentira oficial"'2.

En cualquier caso, sí quiero decir que la visión de Muhammad Šukrī en El pan desnudo es, al igual que otras, una visión parcial hecha desde la perspectiva de la marginalidad. Y en eso radica su originalidad respecto a lo que es línea dominante en el planteamiento que del tema español suelen hacer los escritores árabes. De hecho, muchos de estos escritores, desde Oriente hasta el Magreb, han tratado en sus obras, en numerosas ocasiones, el tema de la España contemporánea o el pasado compartido que constituyó Al-Andalus ${ }^{13}$. Pero en

\footnotetext{
11. A esto alude 'Abd al-Qādir al-Šāwī, Sultat al-wāqi íiyya (Damasco 1981) 300, cuando, refiriéndose a la obra de Šukri, señala: "Todo hay que basarlo en que la etapa colonial, con sus circunstancias generales, no es sino algo secundario, no manifiesto en la biografía, aunque es nota dominante en la conciencia y, por consiguiente, está en el tejido de los recuerdos o es uno de los elementos que influyen en ellos".

12. Pan. Prólogo de Juan Goytisolo, pág. 10.

${ }_{13}$ Véase a cstc respecto la obra de P. Martínez Montávez, Al-Andalus, España en la literatura árabe contemporánea (Málaga 1992).
} 
Šukrī ese halo poético o tópico en lo tocante al tema español desaparece casi por completo ${ }^{14}$. En El pan desnudo la fantasía apenas encuentra lugar, y el relato se centra en una realidad cruda, sin concesiones, sin la nostalgia y la idealización que caracteriza a muchas de las obras y composiciones de tema español que han surgido en la literatura árabe.

Lo español en Šukrī es, por tanto, fruto de su propio entorno vital, puesto que de los catorce capítulos que componen $E l$ pan desnudo, un buen número de éstos se desarrolla en las zonas del Protectorado español. La obra se inicia en el Rif, en su lugar de origen, la anteriormente mencionada cabila de Benī Šìkar, a muy pocos kilómetros de Melilla, donde el hambre y la miseria se adueñan de la familia, como se apunta en la obra:

"Era la época del hambre en el Rif, la sequía y la guerra"15.

La situación les obliga a dirigirse a la ciudad internacional de Tánger, donde cifran sus esperanzas de cubrir las necesidades más elementales:

“-Cállate, vamos a irnos a Tánger. Allí hay pan en abundancia. No llorarás más por el pan cuando estemos allí. En Tánger la gente come hasta saciarse. ¿Ves a tu hermano? Él no llora,"16.

Pero es en ese mismo capítulo primero de la obra cuando ya el Šukrī niño descubre que el éxodo a la ciudad no va a paliar la situación:

"En Tánger no vi las montañas de pan que me había prometido mi madre. También había hambre en este paraíso, pero era menos mortal que en el Rif "

Así se inicia el peregrinaje de Šukrī por diversas ciudades de la zona Norte de Marruecos. Los capítulos segundo y tercero tienen Tetuán como escenario. Orán, en Argelia, es el marco del cuarto capítulo. Quinto, sexto y séptimo de nuevo Tetuán, y desde el octavo hasta el final, el regreso casi definitivo a Tánger. Por tanto, más de un tercio de la obra, cinco capítulos en total, tiene como escenario la ciudad de Tetuán, capital del Protectorado español. En cualquier caso, como veremos, en los capítulos restantes, aunque se desarrollan en Orán, zona de Protectorado francés en Argelia, y en Tánger, zona Internacional, la presencia de lo español es elemento recurrente en las relaciones del protagonista con su entorno.

La vida y el destino de Šukrī, según se narra en El pan desnudo, están desde el principio vinculados a las fuerzas militares españolas a través de su padre. Éste, como se señala en la obra "desertó del ejército español, lo cogieron y lo encarcelaron durante dos años, y desde

\footnotetext{
14. En ibid, 238, refiriéndose a la originalidad de los narradores marroquíes actuales en lo relativo al tema español, señala Martínez Montávez: "En general, se trata de tipos y situaciones más próximas y menos convencionales, tomados de una realidad más inmediata y hasta más sencilla, de una extracción social más humilde y hasta en ocasiones marginada. El detalle adquiere seguramente más significado si se tiene en cuenta que la producción anterior no iba posiblemente por esos derroteros, inclinándose por comunes temas andalusíes o en otras ocasiones por alguno relativo a la actividad colonial española en el país".

15. Pan, 11 .

16. Ibid.

17. Pan, 12 .
} 
que salió de la cárcel se pasa el día cazando moscas en la plaza del Feddan"18. Su deserción del ejército lo lleva a la inactividad, al alcohol, a la violencia, en una larga espiral de destrucción personal y familiar. Precisamente fruto de todas estas circunstancias aparece en El pan desnudo un símbolo utilizado por este personaje para castigar a los suyos: se trata de su cinturón militar, al que Šukrī se refiere en tres ocasiones a lo largo de la obra, relacionándolo siempre con escenas de fuerte violencia paterna:

"Nos pegó a mi madre y a mí con su cinturón militar",

"Mi padre solía sorprenderme en la calle. Me cogía del brazo, me lo retorcía con una mano y con la otra me daba golpes hasta hacerme sangrar. El castigo no terminaba aquí. El grueso cinturón militar me esperaba también en casa",20.

"-Mi padre me pegaba mucho, a veces me colgaba de un árbol y me pegaba con su cinturón militar",

Pero la relación del padre de Šukrī con los españoles afincados en Marruecos no va a quedar interrumpida tras su deserción del ejército, puesto que, desde ese momento hasta su detención, este personaje vivirá en Tánger mercadeando entre los marroquíes y los soldados españoles:

"Mi padre compraba un saco de pan blanco y tabaco barato y se largaba lejos de Tánger para cambiarlo en los cuarteles a los soldados españoles.

Por la tarde, cuando regresaba, traía uniformes militares que vendía en el gran zoco a los obreros marroquíes, ${ }^{\prime 22}$.

Cuando finalmente es detenido, las sospechas recaen sobre los soldados españoles:

“- (...) Deben de ser los soldados españoles los que han detenido a tu padre. Es un desertor del ejército.

Efectivamente, ellos le habían encarcelado, según supimos después. Le delató un soldado marroquí que le conocía de España. Le delató porque mi padre no quiso venderle una manta militar al precio que pretendía. Eso fue, por lo menos, lo que le dijeron a mi madre, ${ }^{\text {,23. }}$.

Como puede apreciarse, la relación inicial entre la familia de Muhammad Šukrī y el entorno español está marcada por la traición y la tragedia. Traición del padre al ejército en cuyas filas ha hallado ocupación; traición de un compatriota marroquí que lo delata ante los españoles; tragedia de una familia que debe buscar su sustento durante los dos años que el cabeza de familia pasa en la cárcel.

\footnotetext{
18. $P$ an, 76 .

19. Pan, 31.

20. Pan, 57.

21. Pan, 76 .

22. Pan, 15 .

23. Ibid.
} 
Tras este desastroso periodo en Tánger, y tras la puesta en libertad del padre, la familia se traslada a Tetuán, ciudad en la que la presencia española es más que notable. Allí, en un seno familiar cargado de la violencia -agravada por el alcohol- del padre, tanto el propio Šukrī como sus progenitores parecen vivir de los españoles. La madre, vendiendo en el barrio Trancat y pregonando en castellano su mercancía, el pequeño haciendo recados para sus vecinos españoles. En cuanto al padre, sin trabajo, se pasa los días comentando las glorias pasadas:

"Mi madre volvió a su negocio de vender legumbres y frutas en El Trancat y mi padre, parado, iba a la plaza Feddan, donde se reunía con los inválidos marroquíes, resultado de la guerra civil española. Algunos se vanagloriaban de ello, porque les había permitido vivir aventuras y tener recuerdos de los combates en los que participaron. Al Caudillo lo apodaban Hadj Franco.

En cuanto a mí, hacía recados para nuestros vecinos españoles" ${ }^{24}$.

En esa misma época tetuaní, empieza el pequeño Šukrī a trabajar de forma continuada en un café, donde toma contacto con el hachís, el kif y el alcohol:

"Trabajaba desde las 6 de la mañana hasta pasada la medianoche. Cada final de mes mi padre se presentaba en el café y el Patrón le obsequiaba con un vaso de té y 30 pesetas, que era mi salario" 25 .

Expulsado del café, y privado de esas 30 pesetas mensuales de las que sólo su padre se beneficiaba, pasa a trabajar en la fábrica de ladrillos por 25 pesetas al mes, cuyo trabajo "consistía en tirar de un carro lleno de tierra o de tejas durante unas 8 ó 9 horas diarias"26. Luego en una alfarería, de limpiabotas y, finalmente, dice: "dejé de limpiar zapatos y me puse a vender el Diario de África" ${ }^{37}$.

Es posible apreciar, a través de los fragmentos anteriormente incluidos, que los precios de las mercancías, en la práctica totalidad de los casos, están expresados en $E l$ pan desnudo en pesetas. El hecho de que el dinero, o más bien la carencia de éste, sea muy importante para Šukrī, queda de manifiesto en las abundantes referencias que al valor de las cosas, o de las personas, hace en su obra. Así, y por citar algunos ejemplos -además de los que se incluyen en otros fragmentos de este estudio- una prostituta española le cobra 15 pesetas $^{28}$, cantidad insignificante frente a las 3.000 que se permite gastar en tres noches seguidas de alcohol, drogas y sexo, y que son el producto de robos de carteras: "No gasté más que 3.000 pesetas", señala ${ }^{29}$. Tener relaciones con una chica virgen cuesta entre 1.000 y $1.500^{30}$, y un

\footnotetext{
24. Pan, 25.

25. Pan, 26.

26. Pan, 33.

27. Pan, 34 .

28. Pan, 39.

29. Pan, 61 .

30. Pan, 60 .
} 
viejo paga a Šukrī por sus servicios sexuales 50 pesetas $^{31}$. Cuatro pesetas cuesta una comida $^{32}$ y 2 un vaso de té verde ${ }^{33}$. En un burdel, varios años después, Šukrī paga 60 pesetas a una prostituta y 25 por una botella de vino ${ }^{34}$. Ya a mediados de los años 50 , en el recurrente escenario del burdel, las prostitutas y el alcohol cuestan a Šukrī unas 300 pesetas $^{35}$.

Su contacto con los bajos fondos españoles en Tetuán está detallado en la visita al burdel de las españolas, donde Šukrī narra las enormes diferencias que, a su modo de ver, se dan entre las prostitutas españolas y las marroquíes en lo relativo a su sexualidad.

Tras la primera etapa tetuaní, Šukrī se traslada a Orán donde, según sus propias palabras en la entrevista concedida a Fernando de Ágreda, llegó en 1949 y pasó alrededor de 2 años $^{36}$. Contaba por tanto el autor, a su llegada a esta ciudad argelina, unos 14 años. En El pan desnudo se confirma este dato:

"Me recordó que cuando se fue del Rif yo tenía cinco o seis años.

-Ya han pasado ocho o nueve años, ${ }^{, 37}$.

La presencia de familiares de Šukrī en Orán se debe al éxodo al que se vieron obligados los rifeños a causa del hambre, y que los llevó hacia las grandes ciudades marroquíes o argelinas. Pero la vida de los rifeños en su exilio no es fácil, algo que es evidente a lo largo de El pan desnudo. Y no sólo por el hambre y las numerosas necesidades por las que atraviesan. La obra deja traslucir una especie de odio ancestral de sus propios compatriotas hacia los rifeños, un pueblo calificado de marginal, inculto, pobre, traidor y asesino:

"De mí solían comentar:

-Es un rifeño, del país de los asesinos y del hambre.

-No sabe hablar árabe.

-Todos los rifeños se mueren de hambre este año.

-Hasta sus animales están enfermos.

-Son ellos los que se los comen, nosotros no. Eso le pone más enfermos.

-Comen hasta carroña. Si se les muere una vaca o una cabra, se la comen.

Cuando van a la ciudad, los niños montañeses sufren la misma humillación que los rifeños, con la única diferencia de que al montañés lo consideran un ingenuo, un idiota, y al rifeño un traidor, ${ }^{38}$.

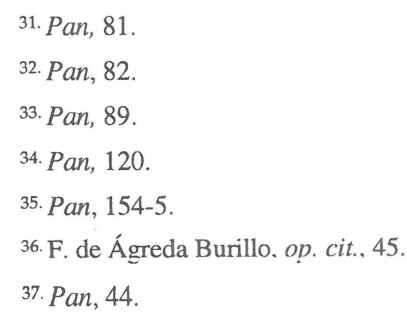


Sin duda, la situación de los rifeños, según se desprende de la obra, es la de una minoría dentro de esa gran masa de desfavorecidos. En un breve diálogo mantenido entre el padre de Šukrī y sus familiares de Orán, se plasma la dura situación de este pueblo, que no ha perdido su dignidad, en el exilio:

"El hombre (...) preguntó a mi padre sobre Marruecos y los rifeños que emigraron. Mi padre le dijo:

-Vivimos miserablemente en el Norte. Por un trabajo te dan un sueldo ridículo. Hay mucha prostitución, pero los rifeños no permiten que sus hijas vayan a los burdeles.

-Aquí en Orán, la vida tampoco es fácil. Pero, mientras podamos conseguir pan y cebolla, nuestra dignidad está a salvo"39.

Respecto al tema de este estudio, y a pesar de trasladarse el escenario a la ciudad de Orán, zona de Protectorado francés, las circunstancias ponen de nuevo en contacto a Šukrī con lo español a través de la esposa del Sr. Segondi, gerente de una plantación de viñedos en la que éste trabaja. Esta mujer, Monique, le habla en español, idioma del que el niño confiesa no conocer más que unas pocas palabras:

"Me habló en español, y yo, turbado, me esforcé por recordar las pocas palabras de ese idioma que sabía y que ya empezaba a olvidar",

Más adelante vuelve a repetir el dato:

"Monique me hablaba en español",

El padre de Monique, de origen español, hace referencia, en un breve diálogo con Šukrī, a la enseñanza de esta lengua en Tetuán:

"Su padre me habló de su origen español. Le dio pena que yo no supiera escribir en ninguna lengua.

-¿Es que no se enseñan el árabe y el español en Tetuán? -me preguntó.

-Sí, me parece que sí.

-¿Y por qué no vas a la escuela?

-A mi padre no se le ocurrió.

-¿Era él quien no quería o eras tú?

-No sé, nunca me negué a ir a la escuela. Somos muy pobres y sin dinero no se puede estudiar", ${ }^{\text {, }}$.

\footnotetext{
38. Pan, 19.

39. Pan, 44.

40. Pan, 46.

41. Pan, 51

42. Pan, 48.
} 
Una visita acompañando a la familia Segondi a Sidi Bel Abbas, ciudad argelina al sur de Orán, brinda la ocasión al autor de mencionar dos breves anécdotas que ponen de manifiesto cierta presencia española en las ciudades argelinas:

"Por las calles, unos españoles hablaban en su lengua. Me enteré después, de que estaban en contra del régimen de Franco. (...) Me tomé un par de vinos en un bar español”,

Tras algunos avatares, Šukrī se plantea regresar con los suyos a Tetuán, ciudad que, aun no siendo su lugar de origen, él considera como suya, frente a Orán, a la que ve como un exilio. Allí la vida no parece haber cambiado: su padre sigue sin trabajo, deambulando por la ciudad, su madre vendiendo fruta y él empieza de nuevo a frecuentar a los rateros, las tabernas y los prostíbulos.

De esta segunda estancia en la capital del Protectorado, Šukrī recoge algunas breves referencias a lo español, que son fiel reflejo del entorno en el que se mueve en esta ciudad. En concreto, tres de ellas relacionan lo español con la opresión, pues se refieren a encuentros puntuales con españoles encargados del orden o la vigilancia: es conducido a la comisaría por un policía español ${ }^{44}$, interrogado por un inspector español ${ }^{45}$, y un vigilante español lo persigue por las calles de Tetuán ${ }^{46}$ el mismo día que decide irse, ya solo, sin su familia, a probar suerte en Tánger.

Frente a estas menciones, aparecen otras tres referencias a lo español, esta vez a lo lúdico: el alcohol, citando el coñac Terry", el vino moscatel y las "dos garrafas de vino español'48 con las que Šukrī y sus amigos riegan sus reuniones.

Cierro esta etapa tetuaní citando las dos menciones a canciones españolas o de tema español que, en dos buenos momentos, afloran de forma natural a la memoria del autor ${ }^{49}$.

De su periplo en Tánger, comenta Šukrī en una entrevista: "Soy como un gran preso en la gran celda que es Tánger, desde 1951 "so. Efectivamente, con 16 años ${ }^{51}$, y 60 pesetas en el bolsillo que le son robadas de inmediato ${ }^{52}$, inicia Šukrī su estancia en esta ciudad, escenario de los siete últimos capítulos de El pan desnudo.

En la ciudad internacional de Tánger, lógicamente el joven Šukrī no tiene ese trato habitual con españoles que se reflejaba en los episodios tetuaníes. Tan sólo, en estos

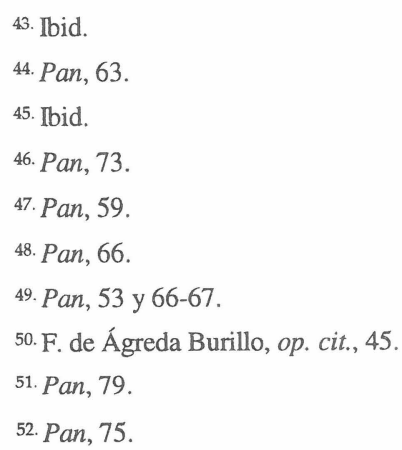


capítulos, se hacen algunas menciones a los acontecimientos ocurridos a raíz del 40 aniversario del Protectorado francés sobre Marruecos, firmado el 30 de marzo de 1912. Se trata de unos altercados violentos que tuvieron lugar en 1952, cuando los marroquíes exigieron la finalización del Protectorado y la independencia de Marruecos:

"-Es un día nefasto.

¿¿Qué quieres decir?

¿¿No lo sabes?

-No.

-Hoy se cumplen cuarenta años de protectorado francés sobre Marruecos. Se firmó el 30 de marzo de 1912, bajo el reinado de Muley Hafid; por eso es un día siniestro.

-¿Y qué es lo que queremos nosotros de los franceses?

-Que se larguen de Marruecos. Hoy termina el contrato del protectorado.

-¿Y los españoles? ¿También queremos que se vayan?

Me miró impaciente.

-No tengo mucho tiempo para hablar de este tema. Sube al otro piso. Allí te informarán unos camaradas" $"$.

Como puede apreciarse a través del fragmento anterior, no se expresa una opinión acerca del Protectorado español, sí del Francés. En las páginas siguientes aparece una serie de consignas revolucionarias que piden el final del colonialismo sobre Marruecos ("iFuera el colonialismo! (...), ¡Viva Marruecos libre! (...), ¡Abajo los traidores! (...) ¡Viva la Guerra Santa!" ${ }^{54}$ Hay muchos muertos y heridos, y se detallan algunos actos violentos. Pero, volviendo al tema objeto de este estudio, lo que más atrae la atención son algunos retazos de conversaciones, en las que se ponen de manifiesto las sospechas que recaen sobre los españoles de ser precisamente ellos los causantes de los disturbios, de estar detrás de estas revueltas, a fin de lograr unos intereses particulares. La primera alusión a la posible responsabilidad española en estos levantamientos tiene lugar cuando Marwani, tachado en la obra de loco, lanza las siguientes palabras:

“-¡Patriotas marroquíes! Todos sabéis que hoy es un día funesto. En un día como hoy, hace cuarenta años, exactamente en 1912, se estableció el Protectorado sobre Marruecos y desde entonces no somos libres"

Aludiendo a este breve discurso, se incluye en la obra un fragmento, en boca de Kebdani, amigo de Šukrī, en el que se especula por primera vez acerca de los posibles intereses españoles en Tánger:

“-Os aseguro que trabaja para un organismo secreto español que trata de abolir el Estatuto de Ciudad Internacional de Tánger para así gobernarla ellos”,

\footnotetext{
53. Pan, 89-90.

54. Pan, 91.

55. Pan, 90.
} 
Algunas líneas más adelante, el protagonista interroga a Kebdani, quien parece estar más y mejor informado de los acontecimientos:

“-Son los españoles los que están detrás de todo esto?

-Eso es lo que dije en el café, ${ }^{, 57}$.

La última referencia en este sentido parece confirmar la implicación de los españoles en la revuelta:

"-¿Alguna novedad? - dije yo.

-Ya está todo claro: han sido los españoles los que han organizado el lío.

-Entonces, ¿era cierto lo que decían de Marwani en el café del Chato?

-Es posible, ¿quién sabe? Lo que sí se sabe es que los españoles son los responsables de esta desgracia.

-Se han aprovechado del aniversario del 30 de marzo y nos han utilizado a los marroquíes como chivos expiatorios" ${ }^{\text {,58 }}$.

Parece evidente que estos hechos no son más que el reflejo de los actos violentos, en pro de la independencia, que tuvieron lugar en Marruecos durante los últimos años del Protectorado, fruto, por una parte, de la fuerte presión ejercida por los partidos nacionalistas -alentados en ocasiones por Franco- y, por otra, de las tensiones surgidas entre Francia y España hacia esos mismos años ${ }^{59}$.

El resto de las referencias al tema español, muy escasas en el escenario tangerino, se sitúan casi exclusivamente en el entorno del vino y las tabernas: se cita una "bodega española" botella del mismo coñac ${ }^{62}$. La única referencia ajena a este entorno es una alusión a un amigo español del autor, Manolo:

"Cuando visité a mi amigo Manolo en el hospital español..." „63

El conjunto de datos incluidos hasta el momento constituye la totalidad de las alusiones que al entorno español hace Muhammad Šukrī en El pan desnudo. No obstante, sí quiero detenerme en una referencia que aparece en repetidas ocasiones a lo largo de la obra. Se trata de la mención de la lengua española, utilizada de forma dispersa por algunos

\footnotetext{
56. Pan, 91 .

57. Pan, 92.

58. Pan, 108.

59. Véase a este respecto: V. Morales Lezcano, España y el Norte de África: el Protectorado en Marruecos (19121956) (Madrid 1986) 223-4.

60. Pan, 96.

61. Pan, 122.

62. Pan, 129.

63. Pan, 145-6.
} 
personajes pero que, a mi modo de ver, es representativa del entorno en el que se desarrolla la novela y la biografía de su autor.

Estas inclusiones de lengua castellana las he dividido en dos grupos bien diferenciados, en el primero de los cuales detallo las ocasiones en las que el autor inserta directamente en su obra frases en esta lengua.

La primera referencia está situada en Tetuán, donde la madre del protagonista vende en el barrio Trancat, y grita en español a los clientes:

"-iVamos a tirar la casa por la ventana!

-iQuien llega tarde no come carne!

-De balde, de balde vendo hoy", ${ }^{64}$.

La segunda, también en Tetuán, forma parte de una conversación mantenida por el protagonista con las prostitutas españolas en un burdel de la ciudad. En dos ocasiones, ellas pronuncian frases en castellano:

"-Uno solamente, nada de dos",

"-Eres fuerte. ¡Eh!"

La última, en Tánger, es una escena cruel, indicativa del estado de pobreza y hambre extremas en el que se halla sumido el joven. Un pescador, en el puerto, tira al mar un trozo de pan que está comiendo. El protagonista, un Šukrī de 16 años, se lanza al agua putrefacta a buscarlo. "El trozo de pan flotaba, el pescador se reía", dice el autor. La escena concluye con dos frases en castellano -posiblemente indicativas de que los pescadores son españoles:

“-iEh!, chico, ven aquí, sólo es una broma, ven. Toma otro pan.

-El otro pescador decía:

-¡Pobre chico! ¡Pobre!, ${ }^{67}$

Las otras menciones no aparecen en la obra directamente en castellano, pero el autor las inserta iniciándolas con frases del tipo: "Lo dijo en español". Son, además de algunas que he ido incluyendo a lo largo de este estudio, las dos siguientes:

La primera hace referencia a la corrupción en Tánger. El protagonista, a su llegada a la ciudad con 16 años, no tiene nada. Un viejo desde un coche lo invita a subir para un encuentro homosexual en las afueras de la ciudad. La escena se inicia con la siguiente frase:

"Un viejo me llamó. Me acerqué al coche, me abrió la puerta y me invitó a subir; me hablaba en español, ${ }^{, 68}$.

\footnotetext{
64. Pan, 35 .

65. Pan, 39.

66. Pan, 40.

67. Pan, 78.
} 
La segunda escena tiene lugar en la Comisaría de Tánger, donde el protagonista está detenido:

"Un policía de paisano entró y habló con el fotógrafo, que era marroquí. Unas veces hablaban en francés y otras en español. Al terminar me preguntó:

¿¿Sabes firmar?

-No.

-¿Cómo le preguntas eso? Es analfabeto, como la mayoría de los marroquíes - dijo en español el policía de paisano.

(...)

El que iba de paisano me preguntó de qué trabajaba. Le contesté en español:

-Nada",69.

En definitiva y tras estos datos, ¿qué conclusiones podrían extraerse acerca de la visión que aporta Šukrī del Protectorado español en Marruecos? Sin lugar a dudas, y como ya dije al principio de este trabajo, es la percepción desde la marginalidad, desde una clase social marcada por la desgracia, el hambre, la miseria, la pobreza más feroz. En general, el protagonista entra en contacto con el entorno español a través de varias vías:

1. Los españoles de los que él o su familia obtienen beneficios económicos (la gente a la que la madre vende fruta, el ejército en el que el padre sirve, el viejo que paga los servicios sexuales de Šukrī, o los recados que él mismo hace a sus vecinos).

2. Los españoles que lo oprimen, a él o a su familia, haciendo su vida más difícil (el ejército español que encarcela al padre desertor, los policías, los vigilantes que persiguen a Šukrī, o los pescadores que se burlan de su miseria).

3. Los elementos españoles que proporcionan placer al protagonista: el alcohol (coñac Terry, vino español) y algunas prostitutas.

4. Por último, un gobierno español sobre el que recaen las sospechas de utilizar a los marroquíes para sus propios fines políticos.

Con estos datos, parece que, en líneas generales, lo que se establece entre Šukrī y lo español es una difícil relación de amor-odio, puesto que de ellos obtiene beneficios y placer por un lado, y castigo, vejaciones y represión por otro.

Por otra parte, en numerosas ocasiones, a pesar de haberse relacionado y de haber conocido los bajos fondos españoles, Šukrī tiende a asociar el ser extranjero con tener acceso a la riqueza, de ahí que en la obra incluya fragmentos en los que inevitablemente

\footnotetext{
68. Pan, 80 .

69. Pan, 137.
} 
compara la forma de vida de los extranjeros con la de los propios marroquíes, constatando las enormes diferencias sociales que se dan entre ambos:

"-Las basuras de la ciudad son mejores que las de nuestro barrio. Lo que tiran los cristianos suele ser mucho mejor que lo que tiran los musulmanes" ${ }^{, 70}$.

"Las caras eran tristes, la pobreza se reflejaba en la ropa y en las casas de tierra y adobe. Las casas más bonitas las tenían los cristianos"

En varias ocasiones alude Šukrī a la presencia de extranjeros, sin determinar que sean españoles, en Marruecos, pertenecientes a clases sociales acomodadas, y de los que se puede obtener beneficios; siempre vistos desde la óptica de la inferioridad social, económica o cultural:

"Sólo una vez conseguí convencer a un viajero extranjero para llevar su pesada maleta",72.

"Una mujer extranjera pagó lo que había comprado y volvió a meter la cartera, llena de billetes, en su bolso, Me sorprendió mirándolo, y lo cogió con fuerza. Su mirada, dulce, me decía: '¿No te da vergüenza?'. Me acobardé y salí del mercado. Es la miseria, señora. Los ricos tampoco tienen vergüenza: nos compran muy barato. Tal vez tú no tengas necesidad de venderte" ${ }^{, 73}$.

La visión que Šukrī tiene del Protectorado español en Marruecos ha de leerse entre líneas: opresión, violencia, abusos, superioridad, desprecio del español hacia el marroquí por un lado; prostitutas, amigos, vino, fuente de subsistencia por otro.

Para terminar, quiero destacar que, en su necesidad de transmitir las duras condiciones en las que se desenvuelve su infancia y primera juventud, Šukrī se convierte en testigo de su tiempo y de su espacio vital, plasmando en El pan desnudo la realidad social de una clase marginada y desfavorecida. Y todo ello en un entorno, el del Protectorado sobre Marruecos, en el que el extranjero posee, en la mayor parte de los casos, el dinero, el poder y la cultura, y donde la presencia europea, como en tantos otros países que han vivido periodos de colonización, produce un importante choque cultural que Šukrī plasma a la perfección en la frase con la que concluyo este trabajo:

"Todo esto pasa por culpa del vino y las mujeres en un país musulmán gobernado por cristianos. No somos ni musulmanes ni cristianos" ${ }^{\text {,74 }}$.

\footnotetext{
70. Pan, 12 .

71. Pan, 42

72. Pan, 79.

73. Pan, 83 .

74. Pan, 130.
} 